Vol. 6 (3), pp. 056-060, June, 2016

ISSN: 2276-7762; ICV: 5.99

Copyright (2016, the copyright of this article is retained by the author(s)

DOI Link: http://doi.org/10.15580/GJBS.2016.3.051616089

http://gjournals.org/GJBS

\title{
A Review of Virus Spread and Transmission in Orange Tree Citrus aurantum in Nigeria
}

\section{*OPARA EU, IKORO Al, and AKINBO OK}

\author{
Department of Plant Health Management, Michael Okpara University of Agriculture, Umudike, \\ Abia State.
}

\section{ARTICLE INFO}

Article No.: 051616089

Type: Review

DOI: 10.15580/GJBS.2016.3.051616089

Submitted: 16/05/2016

Accepted: $27 / 05 / 2016$

Published: 27/06/2016

${ }^{*}$ Corresponding Author

Opara EU

E-mail: euopara22@gmail.com

\section{Keywords:}

virology, viruses, classification, transmission, effects, penetration, forms, and control measures
Virology is the branch of science that deals with the study of viruses. Viruses are microscopic and biological organisms that can replicate only inside the cells of a host organism. Viruses infect all types of organisms, including animals and plants, as well as bacteria and archaea. When infected by a virus, a host cell is forced to produce many thousands of identical copies of the original virus, at an extra ordinary rate. Viruses are found in virtually every ecosystem on Earth.

Forms of variation of viruses are mutation and recombination.

Plant viruses do not have an immediate impact on humans to the extent that human virus do, the damage they do to food supplies have a significant indirect effect. A detailed virus classification and taxonomy is given in Murphy et al. (1995). It is based on virion properties such as size, shape and type of genome, properties of proteins; genome organization and replication; antigenic properties, and biological properties, such as host range, pathogenosity and transmission. Penetration of virus and other pathogens are through mechanical, enzymic or by both means.

Virus mode of transmission is made possible only when there is mechanical injury and transmission can be mechanical, seed, pollen, vegetative and grafting. Virus effects on plant metabolism are mainly on nucleic acids and proteins, lipids, carbohydrates, photosynthesis, respiration, transpiration and low-molecular weight compounds. Plants reactions on parasite entry include migration of significant proportion of the cytoplasm to the point of entry, secretion of papillae to the point of entry and alteration of cell wall to wage the invading pathogen beyond the point of entry.

Conventional control measures of plant viruses are by the removal or avoidance of sources of infection, protecting plants from systemic infection and deployment of resistance.

Citrus Tristeza Virus (CTV) is a virus that affects virtually all the citrus spp in Nigeria and elsewhere in the world where citrus spp are grown. It affects both scion and rootstock, which eventually leads to wilting of the plant. 


\section{INTRODUCTION}

A virus is a set of one or more nucleic template molecules, normally encased in a protective coat or coats of protein or lipoprotein that is able to organize its own replication only within suitable host cell. Within such cells, virus replication is:

a. Dependent on the host's protein-synthesizing machinery.

b. Organized from pools of the required materials rather than by binary fission.

c. Located at sites that are not separated from the host cell contents by a lipo-protein bi-layer membrane and

d. Continually giving rise to variants through several kinds of changes in the viral nucleic acid.

\section{Features of a virus}

The following are features of virus

i. The infecting nucleic acid may be DNA or RNA (but never both) and be single or double stranded. If the nucleic acid is single stranded, it may be of positive or negative sense(positive sense has the sequence that would be used as an MRNA for translocation to give a virus-coded protein)

ii. The mature virus particle may contain polynucleotides other than the genomic nucleic acid.

iii. Where the genetic material consists of more than one nucleic acid molecule, each may be located in size, encoding between 1 and about 250 proteins. Plant viral genomes are not the small end of this range mostly encoding between 1 and 12 proteins. The plant virus proteins may have functions in virus replication, in virus movement from cell to cell, in virus structure, and in transmission by invertebrates or fungi. Animal and bacterial viruses may contain more genes associated with their interactions with their hosts.

iv. Viruses undergo genetic change. Point mutations occur with high frequency as a result of nucleotide changes brought by error in the copying process during genome replication. Other kinds of genetic changes may be due to recombination, re-assortment of genome pieces, loss of genome material or acquisition of nucleotide sequences from unrelated viruses or the host's genome.

v. Enzymes specified by the viral genome may be present in the virus particles. Most of these enzymes are concerned with nucleic acid synthesis.

vi. Replication of many of viruses takes place in distinctive virus-induced structure in the cell.

vii. Some viruses share with certain non-viral nucleic acid molecules, the property of integration into host cell genomes and translocation from one integration site to another.

viii. A few viruses require the presence of another virus for their replication.

\section{Classification of Virus}

A detailed list of the criteria used for virus classification and taxonomy is given in Murphy et al., (1995). The criteria come under four major headings: virion properties, such as size and shape, type of genome properties of proteins; genome organization and replication; antigenic properties; and biological properties, such as host range, pathogenicity, and transmission

\section{Forms of virus}

The two main forms of variation of viruses are mutation (nucleotide changes) and recombination (nucleotide sequence rearrangement). Mutation usually occurs during nucleic acid replication as a result of lack of proofreading of the newly synthesized strand; they can also be induced by external agents such as radiation. Recombination occurs in viruses with genomes consisting of either DNA or RNA. Recombinational events can lead to changes in the genomes of both DNA and RNA viruses and can lead to deletions, additions or exchanges of sequences between two genomes.

Plant viruses require damage to the cuticle and cell wall to be able to enter a plant cell. There is no evidence for a specific entry mechanism such as plasma membrane receptor sites or endo-cytotic uptake as with viruses of vertebrates and invertebrates and it is generally considered that entry is accomplished by " brute force."

Plant viruses are important both economically and as the model system to explore the interactions of viruses and their host cells. They have some properties in common with viruses of other kingdoms and some properties specific to the properties of their plant hosts. Various important virus-like diseases in plants have been shown to be caused by pathogenic RNA known as viriods, which have the following basic properties-

i. viriods are small circular molecules, a few hundred nucleotides long, with a high degree of secondary structure.

ii. Viriods do not code for any polypeptides and replicate independently of any associated plant virus and 
iii. Viriods are the smallest known self replicating genetic unit.

\section{Mode of Entry/Transmission}

The mode of entry of a pathogen into the plant differs depending on the pathogen. Among the important pathogens are the fungi, bacteria, viruses, and nematodes.

The bacteria are the simplest in terms of mode of entry. They can not entirely enter into plant host but their entry is passive utilizing some readymade opening such as stomata, lenticels, wounds created by mechanical factors such as wind, rain storm, etc.

The entry of pathogen (e.g. fungi) into a host cell can be considered into four different phases:

1. The behavior of the pathogen on the surface of the plant which is influenced by the bio-physical environment of the plant.

2. Primary penetration involving a direct penetration of the plant.

3. Entry via other routes e.g. Through injury.

4. Primary reaction of plant towards the arrival of the pathogen.

There are three theories concerning the penetration of pathogen and these include- mechanical means, enzymic means and by both means.

Mechanical penetration involves the use of sphere force to get into or breach the host cuticle. The reason why this is supported is that in some pathogens, penetration is sometimes said to be faster than if it were enzymic means alone.

Enzymic penetration involves the use of enzymes such as pali-nases, cutinases and cellulases. They are of the opinion that it can be done in one operation while others believe that the cuticle wall is first breached, then the pathogen rest for a while and then penetrate the cell wall.

Both the mechanical and Enzymic means according to works done so far show that some fungi (and bacteria) can breach host membrane by the mechanisms of mechanical and enzymic.

\section{Primary Reaction of Plant on Parasite Entry}

i. Migration of significant proportions of the cytoplasm to a point immediately beneath the pathogen. The event usually takes place between the $1^{\text {st }} 6-10$ hours.

ii. Between the cell wall and plasmolemna: There would be deposition of insoluble amorphors materials referred to as papillae between the cell wall and the plasmalemna immediately beneath the pathogen. The papillae are mechanisms of resistance in plant at which the pathogen may not be able to penetrate beyond that point. iii. Alteration of cell wall: This occurs immediately beneath the penetration point and around the pathogen. This was initially thought to be due to degradation of cell wall but it has now been established that cell wall alteration is due to production of chemicals such as alkaloids, phenolic alkaline, lignifications, silica etc.

Transmission is possible as a result of mechanical injury which creates an entry point of the virus. The following ways of transmission are as follows:

a. Mechanical Transmission: This involves the introduction of infective virus or viral RNA into a wound on the plant's surface. When virus establishes itself successfully in the cell, infection occurs. This form of infection occurs naturally with a few viruses such as Tobacco Mosaic Virus (TMV) and Potato Virus X (PVX) that are very stable and reach high concentrations in a plant.

b. Seed Transmission: About one- $7^{\text {th }}$ of the known plant viruses are transmitted through seed of at least one of their infected host plants. Seed transmission provides a very effective means of introducing virus into a crop at an early stage, giving randomized foci of primary infection throughout the plantings.

c. Pollen Transmission: Some viruses are transmitted from plant to plant via pollen as with seed transmission, two mechanisms appear to operate in pollen transmissions: gametic infection of the embryo and direct infection of the mother plant.

d. Vegetative propagation: This is an important horticultural practice, but it is also, unfortunately, a very effective method for perpetuating and spreading viruses. Economically important viruses spread systematically through most vegetative parts of the plants. A plant once systematically infected with a virus usually remains infected for its lifetime.

e. Grafting is essentially a form of vegetative propagation in which part of one plant (scion) grows on the roots (the stock) of another individual. Once the organic uniform has been established, the stock and scion become effectively a single plant. Where either the root stock or the individual from which the scion is taken is infected systematically with a virus, the grafted plant as a whole will become infected if both partners in the graft are susceptible. Grafting may succeed in transmitting a virus where other methods fail.

\section{Effects on plant metabolism}

i. Nucleic Acids and Protein: It is widely assumed that the small RNA viruses have little effect 
on host cell DNA synthesis but there are very few, if any, definitive experiments addressing this question. However, they do have an effect on ribosomes RNA synthesis and the concentration of ribosomes that differs with the virus, strain of virus, time after infection, and the host and tissue concerned. In addition, 70s and 80s ribosomes may be affected differently.

ii. Lipids: The sites of virus synthesis within the cell almost contain membrane structure. Increasing yellow mosaic virus infection alters the ultra-structure of chloroplast membranes rhab-dovirus and tospovirus particles about their outer membrane by budding through some host-cell membrane.

iii. Carbohydrates: Some viruses appear to have a little effect on carbohydrate in the leaves, where as others may alter both their rate of synthesis and rate of translocation. These changes may be illustrated in a simple manner.

iv. Photosynthesis: Virus infection usually affects the process of photosynthesis, with reduction in carbon fixation being the most common effect in leaves showing mosaic or yellow diseases. This reduction usually becomes detectable some days after infection. Photo activity can be reduced by changes in chloroplast and structure, reduces content of photosynthetic pigments or rubisco, or reduction in specific proteins associated with the particles of photosystem. However, such changes appear to be secondary, occurring sometime after infection when much virus synthesis has already taken place.

v. Respiration: For many host-virus combination where necrosis does not occur, there is a rise in respiration rate, which may begin before symptoms appear and continue for a time as disease develops. In chronically infected plants, respiration is often lower than normal. In host-virus combination where necrotic local lesions develop, there is an increase in respiration as necrosis develops. This increase is accounted for, at least in part, by activation of the hexose mono phosphate shunt pathway.

vi. Transpiration: In chronically virus infected leaves, transpiration rate and water content are generally lower than in corresponding healthy tissues. The reported effects over the first 1-2 weeks after inoculation vary.

vii. Low-molecular-weight: There are numerous reports on the at least of virus infection on concentration of low-molecular weight compounds in various parts of virus with different host and viruses and are impossible to interpret in relation to virus replication. The following are some of the effects-A consistent increase in one or both of the amides, glutamine, and asparagines; Phosphorus is a vital component of all viruses and as such may come to represent about one fifth of the total phosphorus in the leaf. In spite of this, there is little or no effect of infection on host phosphorus metabolism; Virus infection frequently involves yellow mosaic mottling or a generalized yellowing of the leaves. Such changes are obviously due to a reduction in leaf pigments, such as carotene and xanthophylls; Virus infection usually appears to affect only the vacuolar anthocyanin pigment in flowers. The pigment residing in chloroplast may not be affected.

\section{Mode of Entry of Citrus Tristeza Virus (Ctv)}

Classification: A member of the genus closterovirus in the family closteroviridae.

Symptoms and Host range: The severity of tristeza or quick decline depends on the virus strain, the citrus spp and the root-stock onto which it has been grafted; it is important on commercial varieties of citrus on sour orange (C. aurantium) root stock. Severe strains cause rapid wilting of the scion, stem pitting of the trunk, and honey combing immediately below the bud union; other milder symptoms include vein yellowing. The host range is mainly limited to the plant family Rutaceae.

Strains: CTV has many strains that show a wide variety of symptoms.

Geographic Distribution: Worldwide, wherever citrus is grown.

Transmission: The virus is transmitted by aphids (mainly Toxoptera citricida and Aphis gosypii)

Particle-Very flexous rod: shaped particles about 2,000 $\mathrm{nm}$ in length and $10 \mathrm{~nm}$ in diameter. Figure Bar $=100 \mathrm{~nm}$ [this figure was published in virus taxonomy, $7^{\text {th }}$ Report of the International Committee on the taxonomy of virus, Masstell, A.A Agranovsky, et al., (MHV. Van Regenmortel, C.m Fauquet, D.H.L. Bishop et al.), Closteroviridae, p. 943-964, copyright Elsevier Academic press, San Diego (2000)].

Genome and Genome Organisation: The genome of CTV is (+)-sense ssRNA of $19.3 \mathrm{~kb}$. It has a 5' caped 3' hydroxyl group and contains 12 ORFs 


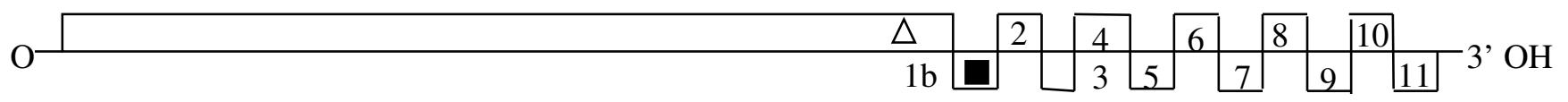

O represents the 5; cap, 3; $\mathrm{OH}$, the 3; hydroxyl group,

+ methyl tranferase domain, $\Delta$ helicase domain, $\boldsymbol{R} \mathrm{R} R \mathrm{R}$ domain. The viral replicate is expressed from ORFs $1 \mathrm{a}$ and $1 b, 1 b$ reading through from $1 \mathrm{a} ; \mathrm{ORF}_{2}$ encodes $\mathrm{a}$ $33 \mathrm{kDa}$ protein of unknown function; $\mathrm{ORF}_{3}$, a $6 \mathrm{kDa}$ hydrophobic protein; $\mathrm{ORF}_{4} 65 \mathrm{kDa}$ homologue of heat shock protein HSP70; orf 5 , a $61 \mathrm{kDa}$ protein involved in virion assembly;

$\mathrm{ORF}_{6}$, the $27 \mathrm{kDa}$ modified coat protein; $\mathrm{ORF}_{7}$, the $25 \mathrm{kDa}$ coat protein; $\mathrm{ORF}_{8}$, an $18 \mathrm{kDa}$ protein and $\mathrm{ORF}_{9}$, a $13 \mathrm{kDa}$ protein, both unknown function; ORF1 $1_{10}$, a 10 $\mathrm{kDa}$ protein and $\mathrm{ORF}_{11}$, a $23 \mathrm{kDa}$ protein, both suppressors of silencing. ORFS2-11 are expressed from subgenomic RNAS.

CTV is the most important virus of citrus and can be a serious constraint to production in Nigeria and elsewhere in the world where it is cultivated. It has the largest genome of any plant virus.

\section{Control Measures}

The three major approaches to conventional control of plant viruses are the removal or avoidance of sources of infection, protecting plants from systemic infection and deployment of resistance.

\section{REFERENCES}

Murphy, F.A., Fauquet, C.M., Bishop, D.H.L., Ghabrial, S.A., Jarius, A.W., Martelli, G.P., Mayo, M.A., and Summer, M.D.(1985).

Roger, H. Comparative plant virology pp270-345.

Roger, H. Comparative plant virology pp 224-225.

Roger, H. Comparative plant virology pp 321.

Roger, H. Comparative plant virology pp 181-185.

Cite this Article: Opara EU, Ikoro Al, and Akinbo OK (2016). A Review of Virus Spread and Transmission in Orange Tree
Citrus aurantum in Nigeria. Greener Journal of Biological Sciences,
http://doi.org/10.15580/GJBS.2016.3.051616089.

